\title{
A NEW BANACH SPACE DEFINED BY EULER TOTIENT MATRIX OPERATOR
}

\author{
MERVE İLKhan AND EMrah Evren KARA
}

Abstract. The main object of this paper is to introduce a new Banach space derived by using a matrix operator which is comprised of Euler's totient function. Also, we determine $\alpha, \beta$, $\gamma$-duals of this space and characterize some matrix classes on this new space. Finally, we obtain necessary and sufficient conditions for some matrix operators to be compact.

Mathematics subject classification (2010): 40C05, 46A45, 47B37, 47B07.

Keywords and phrases: Euler function, Möbius function, sequence spaces, matrix operators, compact operators, Hausdorff measure of noncompactness.

\section{REFERENCES}

[1] B. Altay, F. BAŞAR, The matrix domain and the fine spectrum of the difference operator $\Delta$ on the sequence space $\ell_{p}, 0<p<1$, Communications in Mathematical Analysis 2(2) (2007) 1-11.

[2] B. Altay, F. BAŞAR, Certain topological properties and duals of the matrix domain of a triangle matrix in a sequence space, Journal of Mathematical Analysis and Applications 336 (2007) 632-645.

[3] B. Altay, F. BAŞAR, M. MursaleEn, On the Euler sequence spaces which include the spaces $\ell_{p}$ and $\ell_{\infty} I$, Information Sciences 176 (2006) 1450-1462.

[4] C. Aydin, F. BAşAR, Some new sequence spaces which include the spaces $\ell_{p}$ and $\ell_{\infty}$, Demonstratio Mathematica 38 (2005) 641-656.

[5] F. BAŞAR, Summability Theory and Its Applications, Bentham Science Publishers, İstanbul, 2012.

[6] F. BASAR, E. MALKOWSKY, The characterization of compact operators on spaces of strongly summable and bounded sequences, Applied Mathematics and Computation 217 (2011) 5199-5207.

[7] M. BASARIR, E. E. KARA, On compact operators on the Riesz B(m)-difference sequence spaces, Iranian Journal of Science and Technology 35 (2011) 279-285.

[8] M. BASARIR, E. E. KARA, On some difference sequence spaces of weighted means and compact operators, Annals of Functional Analysis 2 (2011) 114-129.

[9] M. BASARIR, E. E. KARA, On the B-difference sequence space derived by generalized weighted mean and compact operators, Journal of Mathematical Analysis and Applications 391 (2012) 67-81.

[10] M. BASARIR, E. E. KARA, On compact operators on the Riesz $B^{m}$-difference sequence spaces II, Iranian Journal of Science and Technology (Special Issue-Mathematics) 36 (2012) 371-376.

[11] M. CANDAn, Domain of the double sequential band matrix in the classical sequence spaces, Journal of Inequalities and Applications 281 (2012) 15 pages.

[12] M. CAndan, Almost convergence and double sequential band matrix, Acta Mathematica Scientia 34B(2) (2014) 354-366.

[13] E. E. KARA, Some topological and geometrical properties of new Banach sequence spaces, Journal of Inequalities and Applications 2013(38) (2013) 15 pages.

[14] E. E. KARA, M. BASARIR, On some Euler $B^{(m)}$ difference sequence spaces and compact operators, Journal of Mathematical Analysis and Applications 379 (2011) 499-511.

[15] E. E. KARA, M. BASARIR, Ş. KONCA, On some new weighted Euler sequence spaces and compact operators, Mathematical Inequalities and Applications 17(2) (2014) 649-664.

[16] E. E. KARA, M. IlKHAN, On some Banach sequence spaces derived by a new band matrix, British Journal of Mathematics \& Computer Science 9(2) (2015) 141-159. 
[17] E. E. Kara, M. Ilkhan, Some properties of generalized Fibonacci sequence spaces, Linear and Multilinear Algebra 64(11) (2016) 2208-2223.

[18] M. KIRIŞÇI, F. BAŞAR, Some new sequence spaces derived by the domain of generalized difference matrix, Computers \& Mathematics with Applications 60 (2010) 1299-1309.

[19] E. Kovac, On $\varphi$ convergence and $\varphi$ density, Mathematica Slovaca 55 (2005) 329-351.

[20] B. DE MALAFOSSE, V. RAKocEVIC, Applications of measure of noncompactness in operators on the spaces, Journal of Mathematical Analysis and Applications 323 (2006) 131-145.

[21] E. Malkowsky, V. RakoceVIC, An introduction into the theory of sequence spaces and measure of noncompactness, Zbornik radova, Matematicki Inst. SANU, Belgrade, 9(17) (2000), 143-234.

[22] M. Murs aleen, F. Başar, B. Altay, On the Euler sequence spaces which include the spaces $\ell_{p}$ and $\ell_{\infty} I I$, Nonlinear Analysis TMA 65(3) (2006) 707-717.

[23] M. Mursaleen, V. Karakaya, H. Polat, N. Simsek, Measure of noncompactness of matrix operators on some difference sequence spaces of weighted means, Computers \& Mathematics with Applications 62 (2011) 814-820.

[24] M. Mursaleen, S. A. Mohiuddine, Applications of measures of noncompactness to the infinite system of differential equations in $\ell_{p}$ spaces, Nonlinear Analysis 75 (2012) 2111-2115.

[25] M. Murs AleEn, A. K. Noman, On some new sequence spaces of non-absolute type related to the spaces $\ell_{p}$ and $\ell_{\infty} I$, Filomat 25(2) (2011) 33-51.

[26] M. Mursaleen, A. K. Noman, Compactness by the Hausdorff measure of noncompactness, Nonlinear Analysis 73 (2010) 2541-2557.

[27] M. Murs aleen, A. K. Noman, On $\sigma$-conservative matrices and compact operators on the space $V_{\sigma}$, Applied Mathematics Letters 24 (2011) 1554-1560.

[28] M. MuRS ALEEN, A. K. NomAn, The Hausdorff measure of noncompactness of matrix operators on some BK spaces, Operators and Matrices 5 (2011) 473-486.

[29] M. Murs AleEn, A. K. Noman, Compactness of matrix operators on some new difference sequence spaces, Linear Algebra and its Applications 436 (2012) 41-52.

[30] M. Mursaleen, A. K. Noman, Applications of Hausdorff measure of noncompactness in the spaces of generalized means, Mathematical Inequalities \& Applications 16 (2013) 207-220.

[31] I. Niven, H. S. ZuCKerman, H. L. Montgomery, An introduction to the theory of numbers, (5th edition), Wiley, New York, 1991.

[32] V. RAKoceVIC, Measures of noncompactness and some applications, Filomat 12 (1998) 87-120.

[33] H. RoopaeI, D. ForoutanNia, The norm of backward difference operator $\Delta^{(n)}$ on certain sequence spaces, Operators and Matrices 12(3) (2018) 867-880.

[34] E. SAVAŞ, Matrix transformations between some new sequence spaces, Tamkang Journal of Mathematics 19 (1988) 75-80.

[35] I. SCHOENBERG, The integrability of certain functions and related summability methods, The American Mathematical Monthly 66 (1959) 361-375.

[36] M. STIEgLitZ, H. TiETZ, Matrix transformationen von folgenraumen eine ergebnisübersicht, Mathematische Zeitschrift 154 (1977) 1-16. 